\title{
3. LA SENTENCIA CONSTITUCIONAL COMO FUENTE DEL DERECHO
}

\author{
XAVIER PIBERNAT DOMENECH \\ Universidad Autónoma de Barcelona
}


SUMARIO

I.-Los EFEctos dE cosa JuzGada. II.-LOS PLENOS EFECtOS FRENTE A TODOS. 1. El contenido de los plenos efectos. 2. La sujección de todos los ciudadanos y poderes públicos. III.-LA SUJECCION DE LOS JUECES Y TRIBUNALES. IV.- LA SUJECION DEL LEGISLADOR. 1. La autolimitación del Tribunal Constitucional. 2. Las sentencias interpretativas. A MODO DE CONCLUSION. 


\title{
3. LA SENTENCIA CONSTITUCIONAL COMO FUENTE DEL DERECHO
}

\author{
POR \\ XAVIER PIBERNAT DOMENECH
}

Universidad Autónoma de Barcelona

Me propongo en este breve estudio * abordar un tema que, a mi entender, es de la mayor trascendencia para la recta comprensión del ordenamiento constitucional español. Estoy refiriéndome a la incidencia que sobre el sistema de fuentes del Derecho tiene la introducción de una jurisdicción constitucional. Salta a la vista, cuanto menos, que la atribución al Tribunal Constitucional (TC) de la potestad de declarar la nulidad de normas con fuerza de ley incide directamente sobre el sistema de fuentes, puesto que la sentencia que declare la inconstitucionalidad con estos efectos será un acto que tendrá como consecuencia la abrogación de normas susceptibles de valer como tales en el ordenamiento jurídico ${ }^{1}$.

* Este trabajo es el resumen presentado para la realización del segundo ejercicio del concurso para el acceso a una plaza de Profesor Titular en la Universidad Autónoma de Barcelona. De ahí la estructura misma del texto, elaborado para su exposición oral, y la pretensión de hacer un planteamiento global de una lección del programa por mi presentado. He sacrificado, pues, el desarrollo de algunas de las cuestiones concretas que se suscitan al diseño de las líneas maestras de una interpretación general del tema que me ocupa. Doy el texto a la imprenta atendiendo a la amable invitación del Director de esta Revista, pero consciente de su carácter provisional y de que queda pendiente una mayor profundización en muchos de los puntos aquí sólo esbozados.

1 Seguimos la definición de Alesandro Pizzorusso: Corso di Diritto Comparato, Giuffrè, Milán, 1983, pág. 189. Obra de la que sacamos también la referencia a este autor que efectuamos a continuación. Para un estudio general del tema de las fuentes, aunque en referencia al ordenamiento italiano, es del mayor interés Alessandro Pizzourusso: Delle fonti del Diritto, Zanichelli, Bolonia, 1977. 
En este sentido no cabe duda de que la sentencia del Tribunal Constitucional (STC) actúa como fuente del Derecho. Sin embargo, más alla de este aspecto que parece incontrovertible, la cuestión se plantea, por lo que respecta al papel del valor de la jurisprudencia contenida en las STC, en un sistema formal de fuentes construido sobre la identificación entre la disposición jurídica y el Derecho, sin dejar resquicio a la creación judicial del Derecho. Y, justamente, nos movemos dentro de la tradición continental del civil law sustentada de, una parte, en el dogma de la soberanía del legislador, y, por otra, en una concepción oracular de la función judicial, en la que tiene difícil encaje el Derecho de creación jurisprudencial. Se plantea, pues, en el fondo del tema que voy a tratar a continuación, "La sentencia constitucional como fuente del Derecho", no sólo el problema de cual sea el valor de estas sentencias, sino, también, la cuestión de la compatibilidad, por seguir la caracterización que ha efectuado recientemente PIzzorusso, entre un "Derecho Político", basado en apreciaciones de oportunidad, y cuya creación corresponde, en primer término, al legislador, y un "Derecho jurisprudencial», fundamentado en la autoridad de la razón y creado por el juez.

La introducción de una jurisdicción constitucional en el Estado de tradición jurídica romano-germánica ciertamente pone en quiebra el formalizado sistema de fuentes del Derecho, colocando en un primer plano el valor de la jurisprudencia como creadora de Derecho.

Para nuestro objeto, hemos de partir de la caracterización del Tribunal Constitucional. Desde un punto de vista funcional, el art. 1.1. de la Ley Orgánica del Tribunal Constitucional (LOTC) define al Tribunal como «intérprete supremo de la Constitución", lo que si, por sí mismo, significa que su intepretación de la norma fundamental se impondrá a todos, comporta también, como pusieran de relieve RUBIO LLORENTE y ARAGÓN REYES ${ }^{2}$, que el Tribunal se erige en "supremo intérprete constitucional», extendiendo la supremacía de su interpretación a normas distintas de la propia Constitución, y, muy en particular, a la interpretación de la ley.

Intérprete supremo y supremo intérprete son dos cualidades definidoras del TC en razón de las cuales se conforma como órgano jurisdiccional independiente. Organo jurisdiccional que actúa, según corresponde a la función judicial, de acuerdo con las garantías de la «justicia natural» (natural justice) ${ }^{3}$. Esto es, que es un órgano que no dispone de iniciativa propia (jurisdicción rogada), que actúa entre partes en litigio en un procedimiento contradictorio (proceso), y que resuelve en un pronunciamiento motivado (sentencia). Organo independiente (art. 1.1. LOTC), en razón

2 Francisco Rubio llorente y Manuel Aragón Reyes: “La jurisdicción constitucional» en La Constitución española de 1978, estudio dirigido por A. PREDIERI y E. GARCla de ENTERRIA, Cívitas, Madrid, 1980, pág. 815.

3 Vid. MAuro CAPPELLeTt: «EI Tribunal Constitucional en el sistema político italiano: sus relaciones con el ordenamiento comunitario", en $R E D C, n .^{\circ} 4,1982$, págs. 12 y ss. 
tanto de su configuración como órgano jurisdiccional formalmente no inserto en el Poder Judicial y sometido exclusivamente a la Constitución y a su Ley Orgánica (art. 1.1); como por otra parte, de su calidad de organo constitucional, reconocida por el propio artículo 1.1 de la LOTC ${ }^{4}$, de la que deriva su directo sometimiento a la Constitución y su no subordinación a ningún otro poder.

Al TC configurado como órgano jurisdiccional independiente, se le atribuye por la Constitución y su Ley Orgánica un ámbito de competencias que comprende la resolución de litigios muy dispares, pero que coinciden todos ellos en tomar a la norma constitucional como parámetro de enjuiciamiento. Más allá de la especificidad de cada uno de los litigios que corresponde resolver al Tribunal, coinciden todos ellos en ir encaminados en una $u$ otra medida a la garantía del respeto de la Constitución. Tendrá, pues, la STC una doble dimensión: en primer lugar, será siempre la resolución de un litigio en el que las partes enfrentadas asumen intereses para cuya defensa se les legitima; pero en segundo lugar, tendrá un carácter de defensa objetiva de la Constitución. Por consiguiente, como acertadamente señala GARRORENA, las sentencias constitucionales no se agotan en su significación de acto procesal, sino que, además, cobran el carácter de actos creadores de Derecho, $y$, en último término, el carácter de decisiones políticas en cuanto "actos de un poder en dialéctica con los demás poderes del Estado" 5 .

Efectuadas estas consideraciones preliminares, podemos ya adentrarnos propiamente en el análisis de los efectos de las STC, lo cual llevaremos a cabo partiendo de lo que a nuestro modo de ver constituye el punto de arranque de todo estudio de Derecho constitucional, es decir, empezando por la lectura del texto constitucional.

\section{LOS EFECTOS DE COSA JUZGADA}

El artículo 164.1 de la Constitución nos dice respecto de las STC: "Tienen el valor de cosa juzgada a partir del día siguiente de su publicación y no cabe recurso alguno contra ellas». De esta forma se introduce, en referencia al proceso constitucional, un concepto jurídico elaborado por el Derecho procesal, principalmente civil y penal, que responde, por decirlo en pocas palabras, al principio de seguridad jurídica reconocido por el artículo 9.3 de la Constitución, conforme al cual, la sentencia debe

4 Vid. Manuel Garcia-Pelayo: «El status del Tribunal Constitucional», en REDC, número 1,1981 , págs. 28 y ss. pág. 7.

ANGel Garrorena Morales: «La sentencia constitucional» en $R D P O, \mathrm{n} .^{\circ} 11,1981$, 
poner fin al litigio. Al respecto, la doctrina procesal distingue entre cosa juzgada en sentido formal y cosa juzgada en sentido material. En el primer sentido significa que la sentencia que adquiere el valor de cosa juzgada es inimpugnable por las partes del proceso ${ }^{6}$. Y efectivamente, esto es lo que prescribe el artículo 164.1 por partida doble: primero, atribuyendo a la STC valor de cosa juzgada; $y$, en segundo lugar, añadiendo a continuación que «no cabe recurso alguno contra ellas". A pesar de la incorrecta construcción del precepto, su sentido parece inequívoco y, por lo demás, viene confirmado por la LOTC en su artículo 93.1.

No sucede lo mismo en lo relativo a la cosa juzgada en sentido material. Esta se refiere a que el fallo de la sentencia obliga a las que han sido partes en el proceso según el principio non bis in idem. La cosa juzgada en sentido material irradia hacia el exterior impidiendo el replanteamiento ante el juez de la misma cuestión ?. Persigue dicha institución la finalidad de impedir la reproducción de un litigio sobre un mismo objeto y por las mismas partes, lo cual se justifica en el carácter pacificador entre intereses en conflicto que ejercen la función judicial. Mas, no es éste el caso de la jurisdicción constitucional, en la que prima, por encima de la resolución definitiva de un conflicto entre distintos intereses, su carácter de juicio en defensa objetiva de la Constitución. Por lo cual, no es de recibo en el proceso constitucional la cosa juzgada en sentido material ${ }^{8}$, puesto que ello iría contra la posibilidad de que el TC pudiese replantearse su propia doctrina, precisamente cuando una de sus funciones consiste en ir adaptando la Constitución a los cambios sociales y politicos.

Ciertamente, es preciso evitar el replanteamiento de litigios ya resueltos, puesto que si así no fuese, se atentaría contra el principio de seguridad jurídica. Pero ello no forzosamente debe conseguirse mediante la incorporación a las STC de los efectos de cosa juzgada en sentido material, sino que también puede lograrse, tal como ha hecho nuestra LOTC, estableciendo unos plazos muy breves para plantear cada uno de los recursos, de modo que, interpuesto un recurso, la sentencia que lo resuelva se dictará una vez transcurrido el plazo de tiempo dispuesto para el ejercicio de la acción, impidiendo, por consiguiente, su reproducción. Así se establece para el recurso de inconstitucionalidad (art. 33 LOTC), el conflicto de competencias entre el Estado y las Comunidades Autónomas (arts. 62 y 68.3 LOTC), el conflicto de atribuciones entre órganos constitucionales (art. 73 LOTC) y el recurso de amparo (arts. 42; 43.2; 44.2 y 45.2 LOTC). Con lo cual se consiguen los mismos efectos que persigue

6 Vid., por ejemplo, Leonardo Prieto-Castro: Derecho procesal civil, Tecnos, Madrid, 1975 (3. ${ }^{a}$ ed.), vol. $1 .^{\circ}$, pág. 192.

7 Prieto-Castro, ob. cit., pág. 193 y ss.; y Gomez Orbajena y Herce Quemada: Derecho procesal penal, Madrid, 1975, págs. 275 y ss.

8 Sobre el concepto de cosa juzgada construye toda su teoría Raúl Bocanegra Sierra: El valor de las sentencias del Tribunal Constitucional, IEAL, Madrid, 1982. 
la cosa juzgada material en el proceso civil o penal, impedir la reproducción de un proceso ya fallado, pero sin acarrear los inconvenientes que produciria en el proceso constitucional.

Nótese, sin embargo, que no se establece plazo alguno para la interposición de la cuestión de inconstitucionalidad. Lo cual responde a la propia naturaleza de la vía incidental, basada justamente en la posibilidad reconocida al juez de acudir al TC en cualquier momento - "Cuando un órgano judicial considere, en algún proceso...» nos dice el artículo 163 de la Constitución y repite el artículo 35.1 de la LOTC-, y en el reconocimiento al Tribunal de la facultad de conocer sobre una cuestión ya resuelta para confirmar o modificar su doctrina a la luz de nuevos aspectos 0 argumentos, 0 , simplemente, por el cambio de las circuntancias ${ }^{9}$. En definitiva, lo específico de la cuestión de inconstitucionalidad consiste en que deja abierta siempre la posibilidad de enjuiciar la constitucionalidad de una ley. Así, a pesar de lo que establece el discutible y discutido artículo 29 de la LOTC, el TC pudo afirmar en la resolución del primer recurso de inconstitucionalidad, que «si en el futuro se plantearan casos concretos que permitieran apreciar nuevos matices en orden a justificar la oposición -0 disconformidad - a la Constitución de alguno de los preceptos cuya inconstitucionalidad no se declara ahora, el Juez o Tribunal correspondiente podría promover la cuestión de inconstitucionalidad con relación al precepto que le suscitara la duda..." "10.

Por último, en prueba fehaciente de que no se construyen los efectos de la STC sobre el concepto de cosa juzgada material, el artículo 50.2 de la LOTC establece que el TC "podrá" acordar la inadmisión de un recurso de amparo si «hubiera ya desestimado en el fondo un recurso o cuestión de inconstitucionalidad o un recurso de amparo en supuesto sustancialmente igual». Con lo cual, se atribuye al TC una facultad discrecional de admisión, no basada, por ejemplo, en ninguna de las identidades del proceso civil, pero que responde efectivamente al propio sentido del proceso constitucional.

9 La no vinculación del Tribunal a sus propios precedentes es la regla que se sigue en el derecho comparado. Vid. los estudios contenidos en GiUsEPPINo TREVES, (ed.): La dottrina del precedente nella giurisprudenza della Corte costituzionale. Unione Tipografico-Editrice Torinese, Turín, 1971.

10 STC de 2 de febrero de 1981. GaRcIa DE ENTERRÍA no dudó en afirmar la inconstitucionalidad del artículo 29 de la LOTC («La posición jurídica del Tribunal Constitucional en el sistema español: posibilidades y perspectivas" en $R E D C, \mathrm{n} .^{\circ} 1,1981$, págs. 50-52). Por su parte, RUBIO LLORENTE Y ARAGON REYES, destacan el absurdo de una interpretación literal del precepto y buscan su acomodación por la vía de su reinterpretación (ob. cit., páginas 836-838). Sin embargo, algún autor justificó dicho precepto (vid. JeRONIMO AROZAMENA SIERRA: "Valor de la jurisprudencia constitucional" en La Constitución española y las fuentes del Derecho, IEF, Madrid 1979, vol. I, pág. 264).

Como, asimismo, podemos añadir, resulta un precepto vacio el artículo 38.2 de la LOTC, que prohibe el planteamiento ulterior de un recurso de inconstitucionalidad sobre un mismo precepto legal, fundado en infracción de idéntico precepto constitucional, si tenemos en cuenta que el plazo para interponer el recurso es de tres meses desde la publicación de la ley (art. 33 LOTC). 


\section{LOS PLENOS EFECTOS FRENTE A TODOS}

No se agotan, sin embargo, en la cosa juzgada en sentido formal los efectos de las STC, puesto que el último párrafo del apartado $1 .^{\circ}$ del artículo 164 de la Constitución añade: "Las que declaren la inconstitucionalidad de una ley o de una norma con fuerza de ley y todas las que no se limiten a la estimación subjetiva de un derecho, tiene plenos efectos frente a todos". Aunque un sector mayoritario de la doctrina se inclina por atribuir estos «plenos efectos frente a todos" única y exclusivamente a las sentencias que declaren la inconstitucionalidad de una ley ${ }^{11}$, esto es, sólo a las sentencias estimatorias dictadas en resolución de procedimientos de control de constitucionalidad, creemos por nuestra parte que esta lectura es incorrecta ${ }^{12}$. Pues, en efecto, el párrafo citado juega con dos categorías. La primera es la de las sentencias que declaran la inconstitucionalidad de una ley; la segunda, la de las sentencias que no se limitan a la estimación subjetiva de un derecho. Siendo la segunda categoría más amplia y comprensiva de la primera, puesto que, como parece claro, las sentencias que declaran la inconstitucionalidad de una ley no se limitan a la estimación subjetiva de un derecho. Por lo que la atribución de "plenos efectos frente a todos" no corresponde únicamente a las sentencias que declaren la inconstitucionalidad de una ley, sino, por el contrario, a todas aquellas sentencias que no se limiten a la estimación subjetiva de un derecho. Veamos cuáles son éstas.

Para ello debemos analizar los pronunciamientos a que dan lugar cada uno de los distintos tipos de procedimiento de los que conoce el TC. Empecemos con las sentencias dictadas en resolución de procedimientos de control de constitucionalidad, consideradas con independencia de que hayan sido planteadas en vía principal o incidental. Lo primero que importa subrayar es el carácter objetivo del juicio, pues, como afirma el artículo 27.1 de la LOTC, mediante estos procedimientos el TC garantiza la primacía de la Constitución. La sentencia desestimatoria confirma la constitucionalidad de un precepto con fuerza de ley, lo cual muy lejos está de la estimación subjetiva de un derecho, salvo en el caso en el que la desestimación del recurso o cuestión se efectúe por razones de forma,

11 En este sentido se pronuncian Pedro de ElizALde y AYMERICH: «El Tribunal Constitucional y la jurisprudencia” en El Tribunal Constitucional, IEF, Madrid, 1981, vol. I, página 879; Raúl Bocanegra SierRa, ob. cit., págs. 90-95, para quien la expresión “las que no se limiten a la estimación subjetiva de un derecho" es un enunciado vacio; EDUARDO Garcia de Enterria y TomÁs-Ramón Fernández: Curso de Derecho Administrativo, Cívitas, Madrid, 1984, vol. I, págs. 174 y 178-180, para quienes los plenos efectos se limitan a las STC que declaren la inconstitucionalidad de la ley; y SANTIAGo MuÑoz MACHADO: Derecho público de las Comunidades Autónomas II, Civitas, Madrid, 1984, pág. 301.

12 En este sentido, Pablo Perez Tremps: Tribunal Constitucional y poder judicial, CEC, Madrid, 1985, pág. 260; y Enrique Álvarez Conde: El régimen político español, Tecnos. Madrid, 1985 (2. ed.), pág. 498. 
en el que, al no entrarse en la consideración de la conformidad o disconformidad de la ley con la Constitución, la sentencia se limitará a la no estimación del derecho del recurrente. Cuando se trate de una sentencia estimatoria parece incuestionable que tendrá plenos efectos frente a todos. No sólo porque así lo diga expresamente el artículo 164.1 de la Constitución y el propio Tribunal reconozca el carácter erga omnes de sus efectos ${ }^{13}$, sino muy especialmente porque el contenido de su pronunciamiento consistirá en la declaración de inconstitucionalidad de una norma con fuerza de ley con la consiguiente declaración de nulidad del precepto (art. 39.1 LOTC), y obviamente, declarar la nulidad de una norma con fuerza de ley no es la estimación subjetiva de un derecho.

Resulta así que las sentencias que resuelvan procedimientos de inconstitucionalidad, ya declaren la conformidad o disconformidad de la ley con la Constitución, tendrán plenos efectos frente a todos. Pero es que hay más, la distinción entre sentencias estimatorias y desestimatorias para atribuirles unos $u$ otros efectos con carecer de fundamento, tal como hemos mostrado, olvida que en la práctica del TC lo que con mayor frecuencia se hace es dictar sentencias parcialmente estimatorias o parcialmente desestimatorias, en la medida en que solamente se aprecie una parte de la demanda de inconstitucionalidad. En este caso, resulta problemática la atribución de efectos diversos a distintas partes de la sentencia, según sea el sentido del pronunciamiento.

En segundo lugar, debemos detenernos en las sentencias que resuelven conflictos de competencias entre el Estado y las Comunidades Autónomas. En los conflictos positivos, según nos dice el artículo 66 de la LOTC, «la sentencia declarará la titularidad de la competencia controvertida y acordará, en su caso, la anulación de la disposición, resolución o acto que originaron el conflicto en cuanto estuvieren viciados de incompetencia...". Sin embargo, como el TC ha tenido ocasión de aclarar, el pronunciamiento central no consiste en la declaración de la titularidad de la competencia, sino en la anulación de la disposición, resolución o acto viciado de incompetencia y en proceder a «una declaración acerca de la existencia o no de la competencia utilizada para producirlos $y$, eventualmente, acerca de la titularidad de dicha competencia" ${ }^{14}$. Por lo tanto, la declaración de la titularidad, que sí será estimación subjetiva de un derecho, no es más que - como se ha dicho- la "excusa» que sirve a la finalidad de la determinación objetiva de la distribución de competencias $^{15}$. Por lo que respecta al todavia inédito conflicto negativo (art. 72.3 LOTC), creemos que puede aplicarse el mismo argumento que al conflicto positivo.

13 STC, de 2 de febrero de 1981 y STC 150/1985, de 5 de noviembre.

14 STC $11 / 1984$, de 2 de febrero.

15 GERMÁn FERNANDEZ FARRERES: «El sistema de conflictos de competencia entre el Estado y las Comunidades Autónomas en la jurisprudencia del Tribunal Constitucional, REDC, n. 12, 1984, pág. 132. 
Se trate, pues, de un conflicto positivo o negativo de competencias, su objeto principal no es en ningún caso la declaración de la titularidad de la competencia, sino la determinación objetiva de la distribución de competencias. Como dice GARCÍA DE ENTERRIA, estos conflictos «afectan a la esencia misma de la Constitución, a la cuidadosa distribución de poder y de correlativas competencias por ella operada» ${ }^{16}$; como, por lo demás, ha entendido el Tribunal en diversas ocasiones, al decir que la eficacia resolutoria de sus sentencias en los conflictos de competencias se extiende más allá del caso concreto origen del conflicto ${ }^{17}$. En definitiva, podemos concluir que las STC dictadas en resolución de conflictos de competencias tampoco se limitan a la estimación subjetiva de un derecho.

Lo mismo cabe decir respecto de las sentencias que resuelven conflictos de atribuciones entre órganos constitucionales. En este procedimiento, la sentencia determinará a qué órgano corresponden las atribuciones y, en su caso, declarará nulos los actos realizados por invasión de atribuciones (art. 75.2 LOTC). En modo alguno la sentencia se limitará a la estimación subjetiva de un derecho, pues, como ha dicho el TC en el único de estos conflictos que hasta el momento ha resuelto: «El conflicto de atribuciones garantiza (...) la existencia de la misma estructura constitucional concebida como sistema de relaciones entre órganos constitucionales dotados de competencias propias...", para concluir: "El interés preservado por el proceso conflictual es estrictamente el de respeto a la pluralidad o complejidad de la estructura de poderes constitucionales" ${ }^{18}$.

Finalmente debemos referirnos a las sentencias que resuelvan recursos de amparo. Estas pueden denegar u otorgar el amparo (art. 53 LOTC), y en este segundo caso, el artículo 55.1 de la LOTC fija los pronunciamientos que puede contener la sentencia: declaración de nulidad de la decisión, acto o resolución; reconocimiento del derecho o libertad pública, y restablecimiento del recurrente en la integridad de su derecho. $Y$ como ha convenido la mayor parte de la doctrina, la denegación u otorgamiento del amparo afecta primordialmente a las partes en el proceso, consiste en la estimación o desestimación de un derecho subjetivo, tratándose de un procedimiento dirigido contra la violación de los derechos de los ciudadanos ${ }^{19}$. Aunque tampoco, en honor a la verdad, podemos olvidar su dimensión objetiva, ya que, como ha dicho el propio Tribunal, el recurso de amparo "cumple también la finalidad de garantizar el orden jurídico y, en concreto, la observancia de la Constitución» 20.

16 EdUaRdo Garcla de EnTERria, ob. cit., pág. 60.

17 STC 110/1983, de 29 de noviembre y STC 11/1984, de 2 de febrero.

18 STC 45/1986, de 17 de abril.

19 En este sentido, Rubıo llorente y Aragon Reyes, ob. cit., pág. 845; Elizalde y Aymerich, ob. cit., pág. 881; Pérez Tremps, ob. cit., página 267; y alavarez Conde, ob. cit., pág. 498.

20 STC $83 / 1982$, de 22 de diciembre. 
Pero esta consideración no empaña la de que la sentencia que resuelve el recurso de amparo, en principio, propiamente se limita a la estimación subjetiva de un derecho, por lo que no producirá plenos efectos frente a todos, como, por otra parte, viene, incluso, reconocido indirectamente por el artículo 55.2 de la LOTC, que en relación a la llamada "autocuestión de inconstitucionalidad", señala que la nueva sentencia dictada por el Pleno tendrá unos efectos distintos a los de la sentencia de amparo. Por contra, la Ley no señala lo mismo en su artículo 67 para el encadenamiento de una cuestión de inconstitucionalidad a un conflicto de competencias, puesto que en este caso las sentencias que resuelve el conflicto de competencias y la cuestión de inconstitucionalidad producen los mismos efectos.

En definitiva, operando sobre la distinción que efectúa el artículo 164.1 de la Constitución, podemos concluir que las STC, con excepción de las que resuelvan los recursos de amparo, producirán plenos efectos frente a todos. Pasemos ahora a analizar en que consisten tales efectos.

\section{El contenidos de los plenos efectos}

Reconocer «plenos efectos» a las sentencias significa extender más allá del fallo o parte dispositiva de la sentencia los efectos del pronunciamiento del Tribunal. En el aspecto que ahora importa, quiere decir que vincularán todos aquellos razonamientos o argumentaciones jurídicas contenidos en la sentencia como fundamento del fallo. Nos referimos a lo que la doctrina anglosajona denomina la ratio decidendi o la alemana tragende Gründe, aquellos motivos que fundamentan la decisión contenida en el fallo, o dicho de otro modo, que si cambiasen darian lugar a un fallo de signo distinto ${ }^{21}$. Se excluyen, así, aquellas argumentaciones relativas a cuestiones de forma que se efectúan con carácter preliminar, o bien los razonamientos incidentales, los llamados obiter dicta, que al no ser decisivos para el fallo, no tienen en cuenta la totalidad de las consecuencias o aspectos que presenta la cuestión.

Pero, aunque sin duda, la distinción operada dentro de la doctrina sentada en las sentencias de Tribunal tiene su justificación, y no la menor de ellas el que en muchas ocasiones el fallo en si mismo carece de sentido si no se lee a la luz de su motivación, también es verdad que la sutil distinción entre obiter dicta y ratio decidendi sólo puede hacerse caso por caso y quien la realiza, como demuestra la propia experiencia americana,

21 Sobre la ratio decidendi puede verse JosE PUIG BRUTAU: Introducción al derecho civil, Bosch, Barcelona, 1981, págs. 272 y ss.; y en relación a la doctrina alemana, BocaneGRA SiERRA, ob. cit., págs. 61-66. 
es en última instancia el Tribunal, pudiendo en definitiva considerar en la aplicación de un precedente como ratio decidendi lo que hasta el momento venía entendiéndose como obiter o viceversa ${ }^{22}$.

Sin embargo, aceptando esta distinción, que, como digo, será en última instancia una distinción casuística, lo que interesa es señalar que los plenos efectos que alcanzan al fallo y a la doctrina contenida en la ratio decidendi de las STC comportarán el reconocimiento del carácter vinculante de la interpretación jurídica que contengan. Pues no es otra cosa que una operación consistente en precisar el significado "correcto" de los preceptos mediante un razonamiento jurídico es lo que efectúa el Tribunal para pronunciarse.

Hemos de preguntarnos, por consiguiente, cuáles son las normas que interpreta el TC en sus sentencias. Naturalmente que, por encima de todo, en un órgano que se define como intérprete supremo de la Constitución, y resuelve en los distintos procedimientos por la apreciación de la conformidad o disconformidad a la norma fundamental, la respuesta no puede ser otra que, en todo caso, la STC contendrá interpretación de la norma constitucional utilizada como parámetro de enjuiciamiento.

No obstante, no se agota aquí la función interpretativa del TC, puesto que en muchas de sus sentencias debe necesariamente proceder a la interpretación de normas con fuerza de ley. En unos casos la ley será interpretada en tanto que parámetro de enjuiciamiento, así las leyes que integran el «bloque de constitucionalidad» definido por el artículo 28.1 de la LOTC, que servirán para apreciar la conformidad o disconformidad de leyes del Estado o de las Comunidades Autónomas en los procedimientos de control de constitucionalidad (art. 28.1 LOTC), y también en los conflictos de competencias entre el Estado y las Comunidades (arts. 59; 62 y 69.2 LOC). En el mismo sentido, las leyes orgánicas que atribuyan competencias a los órganos constitucionales servirán de parámetro para la resolución de los conflictos de atribuciones que se susciten entre aquéllos (art. 73.1 LOC) ${ }^{23}$. Pero en un segundo aspecto, sin duda el más importante, la ley será interpretada en tanto que objeto del pronunciamiento sobre su constitucionalidad (arts. 161.1.a y $163 \mathrm{C}$; y art. 27 LOC). Será una operación necesaria en todas las sentencias de control de constitucionalidad, y únicamente en ellas, proceder a la interpretación de la ley como paso previo al pronunciamiento sobre su conformidad con la Constitución ${ }^{24}$.

22 Vid. PAUL G. KAUPER: “La regola del precedente e la sua applicazione nella giurisprudenza constituzionale degli Stati Uniti, en G. TREVES, ob. cit., págs. 258-280.

${ }_{23}$ Incluso, como ha reconocido el propio Tribunal, la interpretación de las leyes servirá de parámetro en la solución de los recursos de amparo en tanto entrañe tal interpretación "un tema constitucional de necesario análisis" para la resolución del recurso (STC 52/1982, de 22 de julio).

${ }_{24}$ Debemos añadir que el reglamento administrativo también será objeto de enjuiciamiento por el TC, y por consiguiente, interpretado por el mismo, cuando se impugne en 
En definitiva, lo que realiza el TC para dictar sentencia es interpretar las normas jurídicas, y muy en especial interpretar la norma constitucional. Labor en la que, mediante la determinación del significado "correcto" de los preceptos, se integra el ordenamiento, cubriendo sus lagunas y creando seguridad jurídica. Esta labor, realizada según las reglas de la hermenéutica jurídica, adquiere una especial relevancia en relación a la interpretación de la norma constitucional, la cual, por su mayor amplitud y ambigüedad y por su dimensión política, requiere de la aplicación de específicos criterios de interpretación ${ }^{25}$, acentuando así el carácter creador de la jurisprudencia. Justamente ahí radica la dimensión creadora de la STC como fuente del Derecho ${ }^{26}$. Lo cual, incluso, en cierta medida, no puede ser negado por los que no reconocen a la jurisprudencia el valor de fuente formal, quienes no dejan de reconocer su «trascendencia normativa" y de atribuirle una función "complementadora" ${ }^{27}$.

El contenido de los plenos efectos consiste, en resumen, en el carácter vinculante del fallo y la ratio decidendi, que contenida en el fundamento de la sentencia le sirve de apoyo. Lo cual comporta que la interpretación de la norma constitucional, en tanto que procede del intérprete supremo de la Constitución, pero también de la ley y del reglamento en cuanto corresponden al supremo intérprete constitucional, se integran en la propia norma interpretada, dándole concreto significado. Se vinculan de forma indisociable el precepto y su interpretación por el TC, que realiza así una auténtica función creadora de Derecho.

\section{La sujeción de todos los ciudadanos y poderes públicos}

Debemos preguntarnos ahora quiénes son esos "todos" frente a los cuales las STC tienen, como indica el artículo 164.1 de la Constitución, plenos efectos. En este sentido el artículo no es más que la concreción del fundamental artículo 9.1 de la Constitución que prescribe la sujeción de los ciudadanos y los poderes públicos a la Constitución y al resto del ordenamiento jurídico. Aquél del que resulta que la Constitución -tal como ha dicho el propio Tribunal- «es una norma jurídica, la norma suprema de nuestro ordenamiento, y en cuanto tal, tanto los ciudadanos como los poderes públicos, y por consiguiente también los jueces y ma-

un conflicto de competencias entre el Estado y las Comunidades Autónomas (art. 161.1,c C; y art. 61.1. LOC).

25 Sobre los criterios de interpretación constitucional, puede verse ENRIQUE ALONSO Garcla: La interpretación de la Constitución, CEC, Madrid, 1984; y Antonio-EnRIQue Pérez LUÑo: "La interpretación de la Constitución", $R C G, n .{ }^{\circ} 1,1984$.

${ }_{26}$ Una ya clásica defensa del valor creador de la jurisprudencia en José PUIG BRUTAU: La jurisprudencia como fuente del Derecho, Bosch, Barcelona s.f., pág. 8.

27 Así, Arozamena Sierra, ob. cit., págs. 255-279; y Elizalde y AYMerich, ob. cit., págs. 887 y ss. 
gistrados integrantes del poder judicial, están sujetos a ella» ${ }^{28}$. «Frente a todos" significa, pues, que la STC obliga tanto a los ciudadanos como a todos los poderes públicos.

Empecemos por la sujeción de los ciudadanos. Esta es reconducible a la sujeción de los jueces y Tribunales, puesto que, como se ha dicho: "¿en qué beneficia al ciudadano no tener que acatar una decisión del TC si los demás Tribunales y autoridades están obligados a acatarlas?" 29. Efectivamente, la sujeción de los ciudadanos a las STC se subsume en la sujeción de los ciudadanos a las sentencias de los órganos judiciales (art. $118 \mathrm{C}$ ).

La cuestión se traslada asi a la sujeción de los poderes públicos a las STC. Y tal como explicitan el artículo 38.1 de la LOTC, respecto de las sentencias dictadas en procedimientos de control de constitucionalidad, y el artículo 61.3 respecto de las sentencias que resuelvan conflictos de competencias, que pensamos es también extensible a los conflictos entre órganos constitucionales, las sentencias "vincularán a todos los poderes públicos». Con lo que el legislador optó por introducir en nuestro ordenamiento la categoría elaborada por la doctrina alemana de la Bindungswirkung, esto es, de los efectos vinculantes de las STC que alcanzan a todos los poderes públicos, con excepción del propio TC, que, como es natural, no queda vinculado por su propia doctrina ${ }^{30}$. Los que sí quedan vinculados a las STC son el resto de los poderes públicos. En primer lugar, se hallan sujetos los órganos de la Administración, cuya vinculación no es más que una consecuencia del "sometimiento pleno a la ley y al Derecho" que preceptúa el artículo 103.1 de la Constitución. Sometimiento a las normas según la interpretación que de ellas hagan los Tribunales, que en última instancia, es sujeción a las STC, que se hace efectiva mediante el control de la actuación de la Administración por los órganos judiciales (art. 106.1 C; y art. 8 LOPJ) ${ }^{31}$. La sujeción de los órganos de la Administración de las STC es, pues, al igual que la sujeción de los ciudadanos, reconducible a la sujeción de los jueces y Tribunales.

De este modo venimos a parar en que los «plenos efectos frente a todos" atribuidos a las STC significan, por una parte, la vinculación al fallo y a la ratio decidendi de las mismas, con excepción de las sentencias que resuelvan recursos de amparo, de todos los ciudadanos y poderes públicos, mediante la sujeción de los jueces y Tribunales; y por otra parte, la sujeción del legislador. De una y otra vinculación vamos a ocuparnos a continuación.

28 STC 16/1982, de 28 de abril. Sobre este punto, puede verse EdUARDo GARGIA DE Enterria: “La Constitución como norma jurídica», en Predierl y Garcla de EnTERría, ob. cit., págs. 11-135.

29 Citado por Bocanegra Sierra, ob. cit., pág. 71. ginas $55-56$

3o Un buen resumen de la doctrina alemana en Bocanegra Sierra, ob. cit., pá31 STC 62/1984, de 21 de mayo. 


\section{LA SUJECION DE LOS JUECES Y TRIBUNALES}

El sometimiento "únicamente al imperio de la ley" que prescribe el artículo 117.1 de la Constitución para los órganos integrantes del Poder Judicial comprende el sometimiento a la Constitución, tal como recientemente ha especificado el artículo 1 de la Ley Orgánica del Poder Judicial (LOPJ), así como también comprende el sometimiento a la interpretación jurisprudencial de la Constitución y de la misma ley efectuada por el TC. Resulta ello de la supremacía institucional del TC sobre los órganos del Poder Judicial y del carácter "objetivo" de la interpretación que realiza el Tribunal.

La supremacía institucional del TC, a la que ya nos hemos referido, puede resumirse en su doble cualidad de intérprete supremo de la Constitución y supremo intérprete constitucional. Pues si bien se reconoce al Tribunal Supremo como "órgano jurisdiccional superior en todos los órdenes, salvo lo dispuesto en materia de garantías constitucionales "(art. 123.1 C), al TC corresponde la resolución de las cuestiones de competencia jurisdiccional (art. 4 LOTC), y sus sentencias, a diferencia de las de aquél, jamás pueden ser recurridas. Pero donde con mayor claridad se pone de manifiesto dicha supremacía es, como ha explicado PE. REZ TREMPS ${ }^{32}$, en la articulación procesal de la jurisdicción ordinaria y la jurisdicción constitucional. En primer lugar, en el control de constitucionalidad, en que la cuestión de inconstitucionalidad se plantea por el órgano judicial dejando en suspenso el juicio a quo, que deberá resolverse en función de la STC. En segundo lugar, el artículo 61.2 de la LOTC prevé la suspensión de un proceso ante la jurisdicción contenciosa cuando sobre la misma disposición, resolución o acto se plantee conflicto de competencias ante el TC. En tercer lugar, respecto de la jurisdicción ordinaria, el recurso de amparo se configura en algunos supuestos como recurso extraordinario y subsidiario. En concreto, el amparo contra actos de las autoridades administrativas (art. 43 LOTC) se conforma como recurso subsidiario por el agotamiento de la vía judicial procedente; y el amparo contra actos de los órganos judiciales (art. 44 LOTC), se configura como recurso de tipo casacional.

Pero la sujeción de los jueces y Tribunales a las STC deriva también del carácter "objetivo" de la jurisprudencia en ellas contenida. En efecto, por el juego del principio de seguridad jurídica (art. $9.3 \mathrm{C}$ ) y el de igualdad en la aplicación de la ley (art. $14 \mathrm{C}$ ), la jurisprudencia contenida en las STC se convierte en auténtico precedente para los jueces y Tribunales ${ }^{33}$. Lo cual, si bien se desprende de razones de carácter general

32 Pérez Tremps, ob. cit., págs. 208-223.

33 En este sentido se pronuncian Arozamena Siera, ob. cit., pág. 277; y Manuel Calvo GaAcía: «El valor del precedente judicial en el sistema jurídico español» en De la ju- 
sobre el valor de la jurisprudencia en nuestro ordenamiento, viene reconocido expresamente por el importantísimo artículo 5.1 de la nueva LOPJ. Este dispone: "La Constitución es la norma suprema del ordenamiento jurídico, y vincula a todos los jueces y Tribunales, quienes interpretarán y aplicarán las leyes y los reglamentos según los preceptos y principios constitucionales, conforme a la interpretación de los mismos que resulte de las resoluciones dictadas por el TC en todo tipo de procesos" ${ }^{34}$. De lo cual se desprenden, como concreción de los «plenos efectos frente a todos" que atribuye la Constitución a las STC, que la norma constitucional y su interpretación por el TC vincula a todos los jueces y Tribunales, como asimismo, que la interpretación de las leyes y reglamentos contenida en sus sentencias también los vinculará.

Conviene, no obstante, hacer un par de precisiones al respecto. La primera de ellas es que la jurisprudencia contenida en las sentencias que resuelvan recursos de amparo, a pesar de no producir plenos efectos, también vincula a los órganos judiciales ${ }^{35}$. Y ello es debido a que, con independencia de la prescripción constitucional, entra aqui en juego el valor del precedente jurisprudencial en el ordenamiento español.

La segunda precisión se refiere a que los efectos de la jurisprudencia del TC no se proyectan sólo hacia el futuro, sino que también se proyectan hacia el pasado. Así, con buen criterio, lo establece el artículo 40.2 de la LOTC, que dice que la jurisprudencia de los Tribunales "habrá de entenderse corregida por la doctrina derivada de las sentencias y autos que resuelvan recursos y cuestiones de inconstitucionalidad". Sin embargo, la corrección de la jurisprudencia del Tribunal Supremo, único órgano judicial que la sienta, según el artículo 1.6 del Código Civil, al ser consecuencia del valor del precedente no se limita, creemos, a las sentencias que resuelvan procedimientos de control de constitucionalidad, sino que corresponde a la totalidad de las STC, cualquiera que sea el procedimiento que resuelvan. Por consiguiente, desde la entrada en vigor del artículo 40.2 de la LOTC, ha de entenderse modificado el artículo 1.6 del CC, en el sentido de que, ya no sólo son las sentencias del Tribunal Supremo las que sientan jurisprudencia, sino también las STC, que, en caso de conflicto, prevalecerán sobre aquéllas ${ }^{36}$.

risprudencia del Tribunal Constitucional, Zaragoza, 1985, págs. 310 y ss. En contra, José MANUEL SALA ARQUER: "Consideraciones sobre la cuestión de inconstitucionalidad, en El Tribunal Constitucional, IEF, Madrid, 1981, vol. III, pág. 2.460.

${ }_{34}$ Una crítica al artículo 5.1 de la LOPJ, con la que no coincidimos, puede verse en T. S. Vives: “Tribunal de justicia y jurisprudencia constitucional, en Poder judicial, 2. época, n. 2 , 1986, quien lo califica de "norma incongruente", de casi imposible cumplimiento, $y$, por otra parte, en una norma nula, constitucionalmente ilegítiman (pág. 10).

35 Vid. Calvo Garcia, ob. cit., págs. 310 y ss.

36 MANUEL ARAGON REYES: "Dos cuestiones interesantes en nuestra jurisdicción constitucional; control de las leyes anteriores y de la jurisprudencia", en El Tribunal Constitucional, IEF, Madrid, 1981, vol. I, pág. 573. 
Afirmada la sujeción de los jueces y Tribunales a las STC, debemos preguntarnos cómo se garantiza dicha sujeción. Una primera respuesta podría ir por la vía de señalar el carácter persuasivo de las mismas, resultado del prestigio y autoridad del TC. Evidentemente que este factor no puede ser menospreciado, aunque sin duda resultaría de por sí incapaz de asegurar el sometimiento de los órganos judiciales a la jurisprudencia del TC, como también sería insuficiente para garantizar, dentro del poder judicial, el respeto a la jurisprudencia del TS. Por lo cual es necesario que se articulen técnicas encaminadas a asegurar la supremacía de la jurisprudencia, que por lo que respecta al TC, aunque no hayan sido pensadas para ello, sirven a dicha finalidad. Nos referimos a las técnicas de revisión casuística y a las técnicas de revisión objetiva ${ }^{37}$.

Las técnicas de revisión casuística consisten en la revisión de casos ya resueltos, lo cual, dentro del poder judicial, se consigue estructurándolo siguiendo un modelo piramidal en cuyo vértice se halla el Tribunal Supremo, que resuelve los recursos de casación, sin menoscabo de la independencia de todos los jueces y Tribunales ${ }^{38}$. Ejerce así el Tribunal Supremo dentro del poder judicial una función unificadora y nomofiláctica ${ }^{39}$. Pero cuando se trata de la articulación de dos jurisdicciones distintas, la ordinaria y la constitucional, se plantea de forma más problemática la garantia de la uniformidad interpretativa mediante el sometimiento a la jurisprudencia constitucional. Para dicha función sirve el recurso de amparo, el cual permite que el TC ejerza una revisión de las sentencias de los órganos judiciales ${ }^{40}$. Así lo ha reconocido la Sentencia $2 / 1983$, de 24 de enero, al señalar: «El proceso de amparo es por su naturaleza esencialmente revisor, pues según el artículo 55.1 de la LOTC, puede el TC anular resoluciones judiciales cuando impidan el pleno ejercicio de derechos y libertades protegidas, por lo que tampoco procede admitir que la sentencia judicial constituya cosa juzgada, si se somete al recurso de amparo dentro de plazo, y en tanto éste no se decida". En esta función revisora del recurso de amparo debe distinguirse entre el amparo contra actos de órganos ejecutivos y el amparo contra actos de órganos judiciales. En el primero de ellos, el TC actúa como si se tratara de una última instancia, pues se limita a confirmar o a anular la sentencia del tribunal ordinario, y en este último caso, a decidir sobre la regularidad del acto impugnado. En cambio, en el amparo contra actos

37 Vid. Pérez Tremps, ob. cit., págs. 223-225.

38 Corresponde al TS resolver en casación los recursos por infracción de ley, quebrantamiento de forma, $y$, ahora, según el artículo 5.4. de la LOPJ, también por infracción de precepto constitucional, entendiéndose en todo caso incluida la infracción de «doctrina legal", que equivale a la jurisprudencia reiterada y uniforme del TS, pero que ahora debe comprender, además, la jurisprudencia del TC. Asimismo, el alcance de la casación se ha ampliado, por el artículo 58 de la LOPJ, a la jurisdicción contencioso-administrativa.

39 Perez Tremps, ob. cit., pág. 228.

40 Sobre la naturaleza revisora del recurso de amparo coinciden ARAgón REYES, ob. cit., págs. 571 y ss.; y PéREZ TREMPS, ob. cit., págs. 231 y ss. 
de los órganos judiciales, el TC actúa como si fuese un tribunal de casación, pues su objeto no es el acto originario sino la actuación del órgano judicial, que se enjuicia en relación a la violación de los derechos susceptibles de amparo, pero sin entrar a conocer de los hechos (art. 44.1, $b$ LOTC). Por esta vía se asegura la prevalencia de la posición del TC sobre la de los Tribunales ordinarios.

Sin embargo, y ello es importante subrayarlo, la función revisora que se atribuye al TC debe evitar el peligro de convertir al amparo en una "supercasación», olvidando la diferencia de ámbitos de la jurisdicción ordinaria y la jurisdicción constitucional. Pues, en efecto, como reiteradamente ha podido afirmar el TC, no le corresponde a él el control de la interpretación de las leyes que efectúen los jueces y Tribunales, sino únicamente en tanto que tal interpretación lesione derechos constitucionalmente garantizados 0 resulte constitucionalmente ilegítima ${ }^{41}$. Existe, pues, un límite a la actuación del TC por vía de amparo, el del espacio competencial que con carácter exclusivo asigna el artículo 117.3 de la Constitución a los Tribunales ordinarios, que opera, según lo ha interpretado el Tribunal, sobre la distinción de las cuestiones de legalidad constitucionalmente relevantes, de las que entrará a conocer, y aquellas otras de mera legalidad en las que no debe entrar a conocer la jurisdicción constitucional por quedar reservadas a los Tribunales ordinarios ${ }^{42}$.

Junto a las técnicas de revisión casuistica hallamos las técnicas de revisión objetiva consistentes en la revisión de la interpretación de la Constitución, las leyes y los reglamentos que efectúen los órganos judiciales. La cuestión de inconstitucionalidad es el primero de los procedimientos que sirve a la revisión objetiva, ya que mediante la misma se posibilita que los jueces y Tribunales, de oficio o a instancia de parte, acudan al TC para plantearle dudas acerca de la constitucionalidad de una ley y de la interpretación que de la misma vengan haciendo los órganos judiciales. El mismo efecto revisor objetivo de la interpretación judicial puede conseguirse a través de las autocuestiones planteadas por el propio TC a partir de un recurso de amparo (art. 55.2 LOTC) o de un conflicto de competencias entre el Estado y las Comunidades Autónomas (art. 67 LOTC). Finalmente, debemos aludir a la revisión objetiva de la interpretación judicial que puede efectuarse mediante los conflictos de competencias cuando se impugnen ante el TC actos similares o de ejecución de otros sobre los que anteriormente se hayan pronunciado los tribunales ordinarios.

Con esto concluimos el análisis de la sujeción de los jueces y Tribunales a las STC. Dos cuestiones queremos destacar a modo de resu-

41 En este sentido, pueden citarse, entre otros muchos, el Auto 685/1984, de 14 de noviembre, el Auto 407/1985, de 19 de junio, y el Auto 386/1985, de 12 de junio.

42 Sobre esta cuestión, vid. EDUARDO GaRCIA DE EENTERRIA: «Principio de legalidad. Estado material de Derecho y facultades interpretativas y constructivas de la jurisprudencia en la Constitución”, REDC, n. ${ }^{\circ} 10,1984$. 
men: la primera, es que todas las STC, incluidas las de recurso de amparo, vinculan en su jurisprudencia a los órganos judiciales; en segundo lugar, que las STC no entrarán a conocer de las cuestiones de legalidad ordinaria, reservada a los jueces y Tribunales, sino que solamente en cuanto tengan relevancia constitucional corresponderá su interpretación al TC.

\section{LA SUJECION DEL LEGISLADOR}

La sujeción del legislador a las STC se manifiesta tanto en el carácter de decisión última e inapelable de las mismas respecto de la interpretación de la Constitución y la ley, como asimismo en la capacidad del TC para declarar la inconstitucionalidad de la ley y delimitar las atribuciones del legislador mediante la resolución de los conflictos entre órganos constitucionales. El sometimiento del legislador a las STC es, sin embargo, un sometimiento sólo funcional. TC y legislador $-\mathrm{y}$ nos referimos principalmente al legislador por antonomasia, las Cortes Generales - se configuran ambos como órganos constitucionales, pero entre los cuales a las Cortes corresponde una posición de primacía ${ }^{43}$. Pero, al propio tiempo, el legislador se halla sometido en forma incontrovertible a la Constitución (art. 9.1 C), y por consiguiente, no se configura como órgano soberano, esto es, se halla sujeto a la norma fundamental y a su interpretación por el TC.

Nos enfrentamos asi a lo que a nuestro parecer constituye una de las cuestiones capitales que se plantean en el Estado constitucional contemporáneo: la relación entre la justicia constitucional y la representación popular. Pues, en efecto, no se nos escapa que la progresiva ampliación del control judicial del poder político entraña el peligro de la suplantación del poder constituyente por el TC, o, en último extremo, la sustitución del gobierno de los representantes del pueblo por el gobierno de los jueces ${ }^{44}$.

Para soslayar tan evidente peligro debemos partir de que, tanto al legislador como al TC, les corresponde, mediante la ley en un caso y la

43 La posición de primacia de las Cortes Generales sobre los demás órganos constitucionales es consecuencia de que les corresponde la titularidad de la potestad legislativa (art. 66.2 C), la representación del pueblo español, titular de la soberania (art. 1.2 y 66.1 C), $y$ del status de inviolabilidad que se les reconoce (art. $66.3 \mathrm{C}$ ).

44 Este aspecto es destacado por Miguel A. Aparicio Pérez: “Algunas consideraciones sobre la justicia constitucional y el poder judicial, en $R J C, 1983, n .^{\circ} 4$, págs. 164165; y GIANCARLO ROLLA: “Giustizia costituzionale ed indirizzo politico in Spagna: prime riflessioni sull'esperienza del Tribunale Costituzionale, en Quaderni Costituzionali, 1984, n. 1 , página 123. 
sentencia en el otro, desarrollar y concretar la Constitución ${ }^{45}$. Pero no podemos olvidar su distinta legitimación, que comporta la ineludible necesidad de evitar el solapamiento del TC sobre el legislador, puesto que éste goza de una legitimidad democrática a la que no resulta equiparable la legitimidad del TC.

La respuesta apunta necesariamente a la fijación de unos límites a la actuación del TC. El primer límite lo constituye el que su ámbito de competencias viene definido por la propia Constitución y la Ley Orgánica (art. 161.1 y arts. 2 y 3 LOTC), de lo que resulta su obligación de resolver los asuntos que se le plantean. Bien es verdad que al propio TC se atribuye la resolución de la cuestión de competencia que se susciten (art. 4 LOTC), con lo que indirectamente viene a definir sus relaciones con los demás órganos constitucionales ${ }^{46}$, pero a diferencia del Tribunal Supremo americano que define sus competencias a través de las political questions, nuestro TC no puede ampliar o recortar sus competencias sin incurrir en una violación de la Constitución.

El segundo límite fijado al TC lo constituye la función que se le atribuye. Pues aunque la función de interpretar las normas y declarar la nulidad de éstas con fuerza de ley, es sin duda, como ya hemos tenido ocasión de argumentar, una auténtica creación de Derecho, ello no supone la potestad de crear disposiciones jurídicas. Ahi es donde la función creadora del TC limita con el poder constituyente y el legislador. Su competencia alcanza a la interpretación y expulsión de normas, pero no puede significar en ningún caso la emanación de disposiciones con fuerza de ley, reservada exclusivamente al legislador, y no puede, en definitiva, actuar como legislador positivo.

Si bien la existencia de estos límites a la acción del TC parece fuera de duda, la cuestión que se plantea es la de cómo se garantiza su respeto por el Tribunal con la consiguiente no injerencia en la esfera propia del legislador. Al respecto podemos distinguir entre unas garantías objetivas y unas garantías subjetivas.

La primera de las garantías objetivas consiste en la necesidad de una iniciativa exterior para el inicio de cualquier proceso constitucional. Si esta es una característica general de la función jurisdiccional, en la jurisdicción constitucional presenta un perfil específico, puesto que en ella se restringe la legitimación activa, que se reconoce a unos pocos sujetos en cada caso en función del interés de los mismos y del carácter objetivo del proceso ${ }^{47}$. En definitiva, el TC únicamente tendrá ocasión de pronun-

45 Alonso Garcla, ob. cit., págs. 23-24.

46 Rolla, ob. cit., pág. 133.

47 La legitimación activa viene establecida para el recurso de inconstitucionalidad en el artículo 162.1 a de la C. y en el artículo 32 de la LOTC; para la cuestión de inconstitucionalidad en el artículo 163 de la C. y los artículos 35.1 de la LOTC y 5.2 de la LOPJ; para los conflictos de competencias entre el Estado y las Comunidades por el artículo 60 de la 
ciarse en el caso de que alguno de los sujetos legitimados activamente haya puesto en marcha el proceso constitucional.

La segunda garantía objetiva la constituye el sistema de designación de los Magistrados del TC. En efecto, este sistema ${ }^{48}$, junto con la duración de su mandato y el sistema de renovación por tercios asegura una correspondencia entre las mayorías parlamentarias y la composición del Tribunal, que, sin detrimento de su independencia, comporta una cierta correlación entre la composición del TC y el binomio mayoría parlamentaria-Gobierno, lo que podriamos llamar "sintonía" entre ambos, que pensamos constituye un supuesto de una justicia constitucional que no distorsione el funcionamiento del Estado.

La tercera y última garantía objetiva que se establece al TC consiste en la obligación de motivar jurídicamente sus sentencias. Ciertamente éste es también un rasgo general en el ejercicio de la función judicial (art. 120.3 C), pero que adquiere un valor específico en la jurisdicción constitucional, tanto por la ambigüedad y generalidad propia de la norma constitucional que interpreta, como por el carácter objetivo del proceso. La STC debe contener un razonamiento jurídico que fundamente el fallo como resultado de la aplicación de criterios interpretativos y tomando en consideración los precedentes. Reconocimiento de la importancia de esta fundamentación juridica de la decisión es la introducción de la posibilidad de acompañar a la sentencia de los votos particulares (art. 164.1 C), dissent, en la terminología americana en que se inspira, que refuerzan aún más la exigencia de la fundamentación jurídica de la sentencia. Pues al fin y al cabo, la fuerza de las STC frente al legislador se basará en su autoridad, derivada de la autolimitación en el ejercicio de sus funciones.

\section{La autolimitación del Tribunal Constitucional}

Con la referencia a la autolimitación del TC, el tan llevado y traído selfrestraint de la doctrina americana, entramos de lleno en la consideración de las garantías subjetivas encaminadas a asegurar que el TC no se

LOTC; y para los conflictos entre órganos constitucionales por el artículo 73.1 de la LOTC. Por el contrario, la legitimación activa para interponer el recurso de amparo corresponde a todos los ciudadanos afectados (arts. 53.2 y 162.1 b de la C.; y art. 46 de la LOTC).

48 Según el artículo 159.1 de la Constitución la designación corresponde a efectuarla cuatro al Congreso y cuatro al Senado por mayoría de tres quintos; dos al Gobierno; y dos más al Consejo General del Poder Judicial. De lo cual resulta, teniendo en cuenta la correlación del Gobierno con la mayoría parlamentaria del Congreso, el sistema de designación del CGPJ (arts. 122.3 C. y art. 112 LOPJ), y las mayorías exigidas en las Cámaras, que en la práctica se traducen en el reparto entre los grupos parlamentarios más numerosos, una cierta correspondencia entre la mayoría parlamentaria y la mayoria de los Magistrados. 
extralimite, invadiendo la esfera de actuación del legislador. El fundamento último de esta autolimitación se halla en la propia necesidad del TC de legitimarse de forma permanente y continuada a través de su propia actuación, frente a un legislador que dispone de la legitimidad democrática.

La autolimitación del TC se realiza mediante el desarrollo de una serie de principios jurisprudenciales aplicables a su actividad, en particular decantados en el control de constitucionalidad de las leyes, que por to que respecta a nuestro TC a lo largo de sus seis años de vida pueden resumirse en los siguientes:

\section{1) El principio de congruencia}

Este principio es común a todo el procedimiento jurisdiccional y no consiste en otra cosa que en la correspondencia entre el petitum de la demanda y el pronunciamiento del Tribunal. Como se ha señalado, el principio presenta algunas particularidades en el proceso constitucional ${ }^{49}$, que vienen reconocidas en el artículo 39 de la LOTC. La primera, establecida en el apartado primero de dicho artículo, consiste en la extensión por conexión o consecuencia de la declaración de nulidad de un precepto de una ley a otros de la misma ley, aunque no haya sido solicitada en la demanda ${ }^{50}$. EI apartado 2 del mismo artículo añade una segunda: «El TC podrá fundar la declaración de inconstitucionalidad en la infracción de cualquier precepto constitucional, haya o no sido invocado en el curso del proceso." Con lo cual se amplía la autonomía procesal del Tribunal hasta un punto en que depende de la propia autolimitación el que no se llegue a sustituir el principio de justicia rogada propia de los órganos jurisdiccionales.

\section{2) El principio de conservación de la norma}

Este principio, recogido en nuestro ordenamiento ${ }^{51}$, establece la presunción de constitucionalidad en favor de la norma por el hecho

49 GarrorenA, ob. cit., págs. 9-11.

so Según el propio Tribunal ha especificado en la Sentencia de 8 de abril de 1981, la aplicación del articulo 39.1 de la LOTC "requiere la concurrencia de tres requisitos, que son: $\left.1 .^{\circ}\right)$ Que la sentencia sea declaratoria de la inconstitucionalidad de los preceptos impugnados o de alguno de ellos; $\left.2 .^{\circ}\right)$ Que exista una relación de conexión o de consecuencia entre los preceptos declarados inconstitucionales y aquellos otros a los que la inconstitucionalidad se extiende o propaga, y $3^{\circ}$ ) Que estos últimos pertenezcan o queden comprendidos en la misma Ley, Disposición o acto con fuerza de Ley". Esta doctrina ha sido reiterada en numerosas sentencias posteriores.

51 Prueba de que dicho principio se halla recogido en nuestro ordenamiento, la tenemos en el carácter excepcional con que se prevé la suspensión de la vigencia de las normas cuando se plantea un proceso de control de constitucional (art. 30 LOTC) o un conflicto de competencias por el Estado (art. 64.2 LOTC). 
de proceder de un poder público. Respecto de la misma, ha podido especificar el TC que: «Esta presunción es, además, tanto más enérgica cuanto más directa es la conexión del órgano con la voluntad popular y llega por eso a su grado máximo en el caso del legislador, gue lo es, precisamente, por ser el representante de tal voluntad" 52 . Consecuencia del mismo principio resulta el carácter excepcional de la declaración de inconstitucionalidad de una ley, pues como ha dicho el Tribunal en su Sentencia de 1 de junio de 1981, «Esta potestad sólo puede ser utilizada (...) cuando así lo exigen razones muy graves y sólidas; cuando un órgano constitucional o parte sustancial de él afirman la existencia de esa infracción, o cuando, de no ser declarada dicha infracción, un órgano judicial hubiera de verse en la situación de violar la Constitución (...) - concluyendo--: Cuando estas razones sólidas no existen, el respeto al legislador exige que este Tribunal se abstenga de hacer pronunciamiento alguno.»

\section{3) El principio de interpretación conforme a la Constitución}

Este principio impone al Tribunal la obligación de buscar, siempre que lo haya, el sentido de la ley que sea conforme a la Constitución. El principio de interpretación conforme a la Constitución, el verfassungskonforme Auslegung de la doctrina alemana, deriva del principio de conservación de la norma y permite evitar las lagunas del ordenamiento ${ }^{53}$. El TC, que ha hecho un uso repetido del mismo, lo ha explicitado como derivación del artículo 9.1 de la Constitución, añadiendo: «Esta sujeción de los pooderes públicos al ordenamiento constitucional impone una interpretación de las normas legales acorde con la Constitución, por lo que debe prevalecer en el proceso de exégesis el sentido de la norma, entre los posibles, que sea adecuado a ella" 54 .

\section{4) El principio del respeto al pluralismo político}

Este es el último, aunque no por su importancia, de los principios a los que nos referimos. Puede resumirse en la idea de que «la Constitución deja espacio para la actuación de las fuerzas politicas" 55 , como reconoce nuestra Conetitución al consagrar el pluralismo político. Así, repetidamente el $\mathrm{T}$. ha podido afirmar que su función consiste en fijar a través de la interpretación de la norma

52 STC 66/1985, de 23 de mayo.

53 Vid. García de EnTERRIA: La Constitución como norma jurídica, págs. 135-144.

54 STC 77/1985, de 27 de junio. Criterio también recogido en la STC 122/1983, de 16 de diciembre, y la STC de 2 de febrero de 1981.

55 KonRAD HESSE: Escritos de derecho constitucional, CEC, Madrid, 1983, pág. 21. 
constitucional "los límites dentro de los cuales pueden plantearse legitimamente las distintas opciones políticas» ${ }^{56}$. Y ello es así, porque no se hallan previamente programadas en la Constitución las distintas opciones ${ }^{57}$. Por el contrario, las opciones técnicas o de oportunidad política se deberán desarrollar por los poderes legitimados para ello, no pudiendo inmiscuirse el Tribunal ${ }^{58}$, que se limitará a intervenir excepcionalmente sólo cuando los excesos de aquellos poderes traigan consigo la desnaturalización de alguna institución constitucionalmente garantizada o vulneren los derechos constitucionalmente reconocidos ${ }^{59}$.

\section{Las sentencias interpretativas}

El juego de los distintos principios jurisprudenciales para la autolimitación del Tribunal, en especial del principio de conservación de la norma y el principio de interpretación conforme a la Constitución, junto a la necesidad de evitar las lagunas en el ordenamiento jurídico impone al TC dictar sentencias interpretativas ${ }^{60}$. Por éstas, práctica habitual en Alemania o Italia, se entienden aquellas sentencias que no se limitan a un pronunciamiento sobre la constitucionalidad o inconstitucionalidad de un precepto legal, sino que analizando las posibles interpretaciones del mismo se pronuncian sobre el sentido que es conforme con la Constitución ${ }^{61}$. Con lo cual, al tiempo que en la STC se realiza una determinada interpretación de la Constitución, se establece el significado constitucionalmente correcto del precepto legal, vinculado por partida doble al legislador.

56 STC, de 2 de tebrero de 1981.

57 STC, de 8 de abril de 1981.

58 En este sentido, puede verse la STC $86 / 1982$, de 23 de diciembre; la STC 75/1983, de 3 de agosto; y la STC 76/1983, de 5 de agosto.

59 Vid. STC 38/1983, de 20 de mayo; y STC $77 / 1985$, de 27 de junio.

60 La intrínseca necesidad de estas sentencias es defendida, entre nosotros, por Francisco RuBio LloRENTE: "Sobre la relación entre Tribunal Constitucional y Poder Judicial en el ejercicio de la jurisdicción constitucional', en REDC, n. ${ }^{\circ} 4,1982$, págs. 52 y ss.

61 El Tribunal ha dicho: "Las llamadas en parte de la doctrina sentencias interpretativas, esto es, aquellas que rechazan una demanda de inconstitucionalidad o, lo que es lo mismo, declaran la constitucionalidád de un precepto impugnado en la medida en que se interprete en el sentido que el Tribinal Constitucional considera como adecuado a la Constitución, o no se interprete en el sérntido (o sentidos) que considera inadecuados son, efectivamente, un medio al que la jurisprurdencia constitucional de otros países ha recurrido para no producir lagunas innecesarias en el ordenamiento, evitando, al tiempo, que el mantenimiento del precepto impugnado pueda lesionar el principio básico de la primacía de la Constitución. Es, en manos del Tribunal, un medio lícito, aunque de muy delicado y difícil uso, pero la emanación de una sentencia de este género no puede ser objeto de una pretensión de los recurrentes. El Tribunal Constitucional es intérprete supremo de la Constitución, no legislador, y sólo cabe solicitar de él pronunciamiento sobre adecuación o inadecuación de los preceptos a la Constitución". (STC de 13 de febrero de 1981; reiterado en la STC 77/1985, de 27 de junio). 
Podemos distinguir, dentro las sentencias interpretativas, según la clasificación efectuada por la doctrina italiana, entre las parcialmente desestimatorias y las parcialmente estimatorias.

Las sentencias interpretativas parcialmente desestimatorias son aquellas que desestiman la declaración de inconstitucionalidad de un precepto legal en tanto que sea interpretado en el sentido que especifican los fundamentos de la sentencia. De este tipo se han dado numerosos casos en la práctica de nuestro $\mathrm{TC}^{62}$, y contienen un fallo del siguiente tenor: «Desestimar el recurso de inconstitucionalidad (...) y declarar que dicha Ley no es contraria a la Constitución en cuanto sus preceptos (...) sean interpretados dentro de los límites y en el sentido que se les atribuye en los fundamentos de la presente sentencia» ${ }^{63}$.

Las sentencias interpretativas parcialmente estimatorias son aquellas en las que se declara la inconstitucionalidad de un precepto legal entendido en determinado sentido. En este caso el pronunciamiento del TC será del tipo siguiente: «Que es inconstitucional la disposición (...), interpretada como norma que..." 64 . Como es fácil de ver, la operación que se realiza es la misma que en las sentencias parcialmente desestimatorias, pero en este caso con una formulación en sentido inverso. Nos hallamos, pues, ante dos vías complementarias que sirven para un resultado análogo, puesto que a diferencia de lo que sucede en el ordenamiento italiano ${ }^{65}$, ambos tipos de sentencias producen los mismos plenos efectos frente a todos, y por consiguiente, vinculan igualmente al legislador.

Pero, si bien resultan necesarias y legitimas las sentencias en que el TC, en el ejercicio de su función depuradora del ordenamiento, excluye

62 Hasta el momento podemos citar las siguientes sentencias interpretativas parcialmente desestimatorias: STC, de 8 de abril de 1981; STC, de 29 de abril de 1981; STC, de 19 de noviembre de 1981; STC 5/1982, de 8 de febrero; STC 10/1982, de 23 de marzo; STC 69/1982, de 23 de noviembre; STC 72/1983, de 29 de julio; STC 87/1985, de 16 de julio; STC 178/1985, de 19 de diciembre; STC 29/1986, de 20 de febrero; STC 63/1986, de 21 de mayo; y STC 108/1986, de 29 de julio.

63 STC $5 / 1982$, de 8 de febrero. conocimiento.

64 STC, de 2 de julio de 1981. Es la única sentencia de este tipo de la que tenemos

65 En Italia, debido a que los efectos de las sentencias atribuídos por el artículo 136 de la Constitución se limitan al cese de la eficacia de las leyes declaradas inconstitucionales, sólo se reconocen efectos vinculantes a las sentencias estimatorias. A lo cual si se añade el enfrentamiento en sus primeros años de funcionamiento entre la Corte Constitucional y los Tribunales ordinarios, la llamada "guerra de las dos Cortes", se forzó a la emanación de sentencias parcialmente estimartorias sobre un mismo objeto que otras anteriores parcialmente desestimatorias, las llamadas sentencias manipulativas, con la finalidad de vincular a los jueces y Tribunales ordinarios a la jurisprudencia constitucional. Puede verse al respecto, Gustavo Zagrebelsky: La giustizia costituzionale, II Mulino, Bolonia, 1977, páginas 150-165; y Alessandro Pizzorusso: “Las sentencias "manipulativas" del Tribunal Constitucional italiano", en El Tribunal Constitucional, IEF, Madrid, 1981, vol. I, págs. 279. 296. 
algunas interpretaciones de la ley por no ser conformes a la Constitución, en ocasiones, el Tribunal no se limita a ello, inmiscuyéndose en la función legislativa. Así ha sucedido en diversas sentencias que, por regla general, han resultado muy polémicas dentro del propio Tribunal, como demuestran los votos particulares que las acompañan.

En primer lugar, podemos citar aquellas sentencias en las que el Tribunal no se limita a efectuar un juicio para precisar el significado constitucional de la ley, sino que, por via interpretativa, procede a la reconstrucción de un precepto suplantando al legislador. Así, en relación a una cuestión de inconstitucionalidad por violación del principio de igualdad, presentada contra el artículo 160 de la Ley General de la Seguridad Social, por no reconocer pensión de viudedad en favor del viudo, se procede a modificar la ley en el sentido de que dicho artículo incluya tanto a la viuda como al viudo ${ }^{66}$. En otra ocasión, la Sentencia $27 / 1985$, de 26 de febrero, que resuelve una cuestión de inconstitucionalidad presentada contra el artículo 13 del Código de Justicia Militar, por violación del artículo 24 de la Constitución, además de declarar parcialmente inconstitucionales los artículos 13.1 y 14 de la mencionada ley, procede a redactar de nuevo los citados artículos, ejerciendo una función que creemos sólo compete al legislador.

En otras ocasiones, el Tribunal procede a efectuar recomendaciones al legislador. En este sentido, resulta paradigmática la Sentencia 3/1983, de 25 de enero, que resuelve una cuestión de inconstitucionalidad presentada contra el artículo 170 de la Ley de Procedimiento Laboral, en la que el Tribunal no se recata en afirmar en el fundamento $5^{\circ}$, que: "Sería conveniente que el legislador para superar la excesiva rigidez de la norma, reformara el artículo 170 y conexos..." ${ }^{67}$. En el mismo sentido, la Sentencia $76 / 1983$, de 5 de agosto, en recurso previo contra la LOAPA, efectúa diversas recomendaciones al legislador, no justificadas porque se trate de un recurso previo, del siguiente tipo: "convendría que el legislador precisase el alcance de la referencia..."; «Es necesario que el legislador elimine la ambigüedad del texto..."; o bien, "El legislador debe precisar el contenido de la referencia..."

Finalmente, no podemos dejar de referirnos a la Sentencia $53 / 1985$, de 11 de abril, que resuelve el recurso previo planteado contra

66 A esta sentencia se acompaña un voto particular del Magistrado Arozamena Sierra, al que se adhiere el Magistrado Pera Verdaguer, en la que manifiesta su discrepancia por considerar que el Tribunal hace una «innovación por la vía de la sentencia en el derecho de la Seguridad Social". Por su parte, el Magistrado Rublo Llorente acompaña otro voto particular en el que manifiesta que «esta supresión es una medida de política legislativa cuya oportunidad y forma sólo el legislador ha de determinar...".

67 En un voto particular, el Magistrado Arozamena Slerra señala: «si la norma en. juiciada se reputa constitucional y no se ha excluido entre sus interpretaciones posibles las no conformes a la Constifución, no me parece que puedan recomendarse $-y$ menos imponerse- cánones o criterios interpretativos". 
el proyecto de Ley Orgánica de reforma del Código Penal sobre despenalización del aborto, sin duda una de los más discutibles y polémicos pronunciamientos del TC, como demuestran los numerosos votos particulares que la acompañan, en la que, amparándose en el carácter de recurso previo, el Tribunal impone auténticos mandatos al legislador, con una justificación de este tenor: «como es obvio, el legislador puede adoptar cualquier solución dentro del marco constitucional, pues no es misión de este Tribunal sustituir la acción del legislador, - sin embargo, prosigue -, pero sí lo es, de acuerdo con el artículo $79.4, b$ de la LOTC, indicar las modificaciones que a su jusicio - y sin excluir otras posibles- permitirán la prosecución de la tramitación del Proyecto por el órgano competente" 68 .

En definitiva, como acabamos de mostrar, el TC en algunas ocasiones se extralimita, yendo más allá de su función interpretativa, con la facultad de declarar la inconstitucionalidad de las leyes, para erigirse en legislador positivo. Pues, como el mismo Tribunal tuvo ocasión de precisar en uno de sus primeros pronunciamientos: «Puede el Tribunal establecer un significado de un texto y decidir que es conforme con la Constitución", pero añadiendo seguidamente: "No puede en cambio tratar de reconstruir una norma que no esté debidamente explicita en un texto, para concluir que ésta es la norma constitucional» ${ }^{69}$. Así, la autolimitación del TC se constituye en la principal garantía del respeto al legislador. Pero ésta, no sólo juega en favor de aquél, sino que, asimismo, la autolimitación del Tribunal va en favor de su propia autoridad, que, en última instancia, es lo que asegura la sujeción del legislador a las STC. Si la auctoritas, como dice GARCía PELAYO, se basa en el crédito de una institución actualizada en una conducta ejemplar ${ }^{70}$, podemos decir que el so-

68 Esta afirmación suscita el rechazo de la mitad de los Magistrados, quienes se manifiestan en los votos particulares que acompañan a la sentencia en el siguiente sentido: la sentencia sha concluido (...) con un pronunciamiento que traspasa los límites jurídicofuncionales de la potestad jurisdiccional que incumbe al Tribunal Constitucional" (voto particular de Arozamena Sierra); "Tampoco creo que sea función del Tribunal colaborar en la función legislativa, orientarla o perfeccionárla" (v.p. Díez-Picazo); "La jurisdicción constitucional es negativa, puede formular exclusiones o vetos sobre los textos a ella sometidas. Lo que no puede hacer es decirle al legislador lo que debe añadirse a las Leyes para que sean constitucionales. Si se actúa así, y así ha actuado en este caso este Tribunal, se convierte en un legislador positivo» (v.p. Tomás y Valiente); "Tal función excede de las ya muy amplias competencias que no sólo la Constitución, sino también la LOTC, asignan a este Tribunal Constitucional, cuya actuación no puede aproximarse a la de una tercera Cámara sin provocar un peligroso desequilibrio en nuestro sistema jurídico-político, invadiendo facultades que corresponden al poder legislativo" (v.p. Latorre Segura y Diez de Velasco VaIlejo); y, finaimente, "el Tribunal impone a las Cortes sus propias preferencias de política legislativa, y esta imposición, que no encuentra naturalmente, base alguna en la Constitución o en la Ley, es arbitraria» (v.p. Rublo Llorente).

69 STC, de 8 de abril de 1981.

7o Manuel Garcla-Pelayo: Idea de la política $y$ otros escritos, CEC, Madrid 1985, pág. 139. 
metimiento del legislador a las STC se basará, en último término, en la autoridad que adquiera el TC en el buen ejercicio de sus competencias, sin sobrepasar nunca los límites fijados a su esfera de actuación.

\section{A MODO DE CONCLUSION}

Hemos llegado al final de esta exposición. Nos corresponde antes de poner punto final, tratar de resumir brevemente una serie de conclusiones que formulamos a título provisional:

1. Los efectos de las STC no se construyen, en nuestro ordenamiento, sobre la categoría de cosa juzgada, tal como intenta demostrar BOCANEGRA y ha seguido parte de la doctrina ${ }^{71}$, sino que únicamente se recoge tal categoría en sentido formal, en relación a la irrecurribilidad de todas las STC.

2. Todas las STC vinculan a los jueces y Tribunales, según ha reconocido recientemente de modo expreso el artículo 5.1 de la LOPJ, vinculación en la que se subsume la vinculación de los ciudadanos y poderes públicos, pero que vinculan con dos fundamentos distintos: Las sentencias que resuelven recursos de amparo sólo vinculan en tanto que constituyen precedentes jurisprudenciales que, por el juego de los principios de igualdad en la aplicación de la norma y de seguridad jurídica, deben ser seguidos por todos los órganos judiciales. En cambio, el resto de las STC vinculan, además, porque se les atribuyen expresamente por la Constitución "plenos efectos frente a todos".

3. La consecuencia singular de los "plenos efectos frente a todos" consiste en que las STC, a excepción de las que resuelven recursos de amparo, vinculan también al legislador en la declaración de inconstitucionalidad de una ley, en la interpretación de la norma constitucional, y, por último, también en la interpretación que efectúen de la ley, en especial de la realizada mediante las denominadas sentencias interpretativas.

4. No obstante, la interpretación de la ley, o, en su caso, del reglamento, que se efectúe en las STC debe limitarse a aquellas cues-

71 Siguen la posición de Bocanegra tanto García de Enterría en su Curso de Derecho Administrativo, ob. cit., como Santiago Muñoz Machado en su Derecho público de las Comunidades Autónomas, ob. cit., vol. II. 
tiones de relieve constitucional, no inmiscuyéndose en las cuestiones de legalidad ordinaria, cuya interpretación corresponde a los jueces y Tribunales, ni tampoco en la apreciación de la oportunidad política o técnica de la ley, que sólo corresponde efectuar al legislador.

5. Las STC deben ser consideradas, así, como fuentes del Derecho, y no únicamente porque puedan declarar la nulidad de una norma, sino, especialmente, porque la interpretación de las normas contenidas en su jurisprudencia se liga indisolublemente a la norma interpretada, convirtiendo a la sentencia, desde este punto de vista, en auténtica creadora de Derecho.

6. La posición que la jurisprudencia del TC ocupa en el sistema jerárquico de fuentes, $y$, en concreto, la interpretación de la ley, no es superior a la propia ley, apareciendo un escalón intermedio entre la Constitución y la ley, tal como han apuntado LOPEZ GUERRA ${ }^{72}$ y PÉREZ RoYo ${ }^{73}$, sino que, por el contrario, la interpretación de la norma contenida en la STC se identifica con la norma intepretada, ocupando en la jerarquía de fuentes el rango de aquélla.

7. La introducción de la jurisdicción constitucional, con el consiguiente reconocimiento de la sentencia constitucional como fuente del Derecho, si bien no altera la jerarquía de fuentes, introduce una quiebra en la correlación jerarquía de las fuentes-jerarquía del órgano productor que caracteriza un sistema formalizado, poniendo en primer plano la cuestión de la creación jurisprudencial del Derecho. Con lo cual, venimos a parar en el planteamiento de la cuestión de la legitimidad del juez constitucional o a preguntarnos sobre qué criterios decide. En definitiva, y con esta consideración finalizamos, se plantea en el fondo el problema de los criterios de interpretación constitucional, si se trata de límites sustantivos, como afirman DWORKIN y TRIBE, o bien de límites procedimentales, como afirma ELY, por referirnos a los protagonistas de la reciente polémica americana. En último término, se trata del problema de fondo del constitucionalismo, del problema de la limitación del poder por el Derecho.

72 LUIS LOPEZ GUERRA: “El Tribunal Constitucional y el principio stare decisis» en El Tribunal Constitucional. IEF, Madrid, 1981, vol. II, pág. 1439.

73 Javier Perez Royo: Las fuentes del Derecho, Tecnos, Madrid, 1984, pags. 48-51. 